\section{Value of sagittal color Doppler ultrasonography as a supplementary tool in the differential diagnosis of fetal cleft lip and palate}

\author{
Myoung Seok Lee', Jeong Yeon Cho ${ }^{2,3}$, Sang Youn $\mathrm{Kim}^{2}$, Seung Hyup $\mathrm{Kim}^{2,3}$, \\ Joong Shin Park ${ }^{3,4}$, Jong Kwan Jun ${ }^{3,4}$ \\ 'Department of Radiology, Seoul Metropolitan Government-Seoul National University \\ Boramae Medical Center, Seoul; ${ }^{2}$ Department of Radiology, Seoul National University \\ Hospital, Seoul; ${ }^{3}$ College of Medicine, Seoul National University, Seoul; ${ }^{4}$ Department of \\ Obstetrics and Gynecology, Seoul National University Hospital, Seoul, Korea
}

Purpose: The purpose of this study was to evaluate the feasibility and usefulness of sagittal color Doppler ultrasonography (CDUS) for the diagnosis of fetal cleft lip (CL) and cleft palate (CP). Methods: We performed targeted ultrasonography on 25 fetuses with $\mathrm{CL}$ and $\mathrm{CP}$, taking coronal and axial images of the upper lip and maxillary alveolar arch in each case. The existence of defects in and malalignment of the alveolus on the axial image, hard palate defects on the midsagittal image, and flow-through defects on CDUS taken during fetal breathing or swallowing were assessed. We compared the ultrasonography findings with postnatal findings in all fetuses. Results: Alveolar defects were detected in 16 out of 17 cases with CP and four out of eight cases with CL. Alveolar malalignment and hard palate defects were detected in 11 out of 17 cases and 14 out of 17 cases with CP, respectively, but not detected in any cases with CL. Communicating flow through the palate defect was detected in 11 out of 17 cases of CL with CP. The accuracy of detection in axial scans of an alveolar defect and malalignment was $80 \%$ and $76 \%$, respectively. Accuracy of detection of in mid-sagittal images of hard palate defect and flow was $80 \%$ and $86 \%$, respectively. The overall diagnostic accuracy of combined axial and sagittal images with sagittal CDUS was $92 \%$.

Conclusion: Sagittal CDUS of the fetal hard palate is a feasible method to directly reveal hard palate bony defects and flow through defects, which may have additional value in the differential diagnosis of fetal $C L$ and $C P$.

Keywords: Ultrasonography, prenatal; Cleft lip; Cleft palate; Ultrasonography, Doppler, color; Congenital abnormalities

\section{Introduction}

Orofacial clefts, including cleft lip $(C L)$ with or without cleft palate $(C P)$, are relatively common

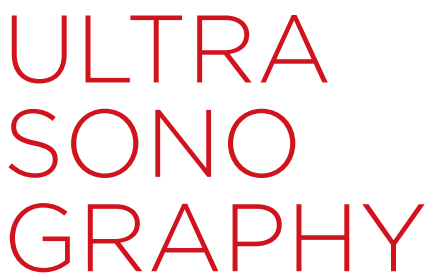

ORIGINAL ARTICLE

https://doi.org/10.14366/usg.16025 pISSN: 2288-5919 e elSSN: 2288-5943 Ultrasonography 2017;36:53-59

Received: May 18, 2016

Revised: July 28, 2016

Accepted: August 6, 2016

Correspondence to: Jeong Yeon Cho, MD, Department of Radiology, Seoul National University Hospital, 101 Daehak-ro, Jongno-gu, Seoul 03080, Korea

Tel. +82-2-2072-3074

Fax. +82-2-747-7418

E-mail: radjycho@snu.ac.kr

This is an Open Access article distributed under the terms of the Creative Commons Attribution NonCommercial License (http://creativecommons.org/ licenses/by-nc/3.0/) which permits unrestricted noncommercial use, distribution, and reproduction in any medium, provided the original work is properly cited.

Copyright @ 2017 Korean Society of Ultrasound in Medicine (KSUM)

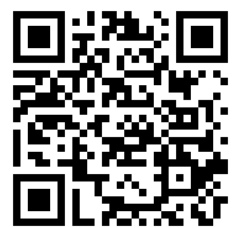

How to cite this article:

Lee MS, Cho JY, Kim SY, Kim SH, Park JS, Jun JK. Value of sagittal color Doppler ultrasonography as a supplementary tool in the differential diagnosis of fetal cleft lip and palate. Ultrasonography. 2017 Jan;36(1):5359. 
congenital anomalies, reported in approximately one in 700 live births [1]. The rates of $C L$ with or without $C P$ are higher in parts of Latin America and Eastern Asia and lower in South Africa and Southern Europe [2]. The accurate prenatal detection and differential diagnosis of $\mathrm{CL}$ and $\mathrm{CP}$ is of clinical importance because the type and extension of clefts are correlated with fetal outcomes and associated anatomical and chromosomal abnormalities $[3,4]$. $\mathrm{CL}$ without $\mathrm{CP}$ is generally known to show favorable prognosis compared to $\mathrm{CL}$ with $\mathrm{CP}$. Reconstruction techniques, surgical implications, and risks for chronic otitis media, hearing loss, and abnormal speech are very different when the palate is involved. $\mathrm{CL}$ with $\mathrm{CP}$ includes greater morbidity and reparations resulting in more extensive surgeries.

Transabdominal ultrasonography (TA-US), performed in the second trimester of pregnancy, is the first choice of imaging modalities to screen for orofacial clefts due to its easy accessibility and the fact that it does not result in radiation exposure. In low-risk groups (unselected population-based groups of pregnant women), the overall detection rate for all types of clefts was reported as $0 \%$ $70 \%$, for $\mathrm{CL}$ with or without $\mathrm{CP}$ it was $33 \%-88 \%$, and for isolated $\mathrm{CP}$ it was $0 \%-22 \%$ [5]. There have been some prospective studies for the detection and identification of $C L$ and $C P$ in high-risk groups (i.e., referral cases because of abnormal findings during routine prenatal screening ultrasonography [US], family history of $\mathrm{CL}$ or $\mathrm{CP}$ ). The reported detection rate in these cases using 2-dimensional (2D) TA-US was $91 \%-96 \%$ for $C L$ with or without CP and $41 \%-49 \%$ for $\mathrm{CL}$ with $\mathrm{CP}[6-8]$. For the high-risk group in these studies, using 3-dimensional (3-D) TA-US improved the detection rate to $100 \%$ for $C L$ with or without $C P$ and $41 \%-46 \%$ of $C L$ with CP [6-8]. Some additional scan techniques have been introduced for 3-D US, such as the reverse face view [9] or flipped face view [10], to improve the diagnostic accuracy of detection and identification of $\mathrm{CL}$ and $\mathrm{CP}$.

However, 3-D US takes a longer time to execute a scan and, in the majority of cases, needs a customized volume transducer. Hence, conventional 2-D US is still important as the first-line imaging modality for the prenatal diagnosis of $\mathrm{CL}$ and $\mathrm{CP}$. Efforts to enhance the accuracy of 2-D US, including the application of color or power Doppler have been reported [11-13]. A conventional grayscale ultrasound may miss the existence of $\mathrm{CP}$, because acoustic shadowing from the bony alveolar ridge often obscures the palate defect. Previous communications reported that the color or power Doppler on the sagittal plane can improve the diagnostic accuracy of $\mathrm{CP}$ by detecting the slow amniotic fluid flows between the buccal space and the nasal fossa during breathing or swallowing, with representative cases at the level of case reports [11-13]. However, to our knowledge, there have been no previous studies validating the use of color Doppler ultrasonography (CDUS) on the sagittal plane in the diagnosis of $\mathrm{CL}$ and $\mathrm{CP}$.

Thus, the aim of our study is to evaluate the feasibility and usefulness of sagittal CDUS for the diagnosis of fetal CL and CP.

\section{Materials and Methods}

This prospective study was approved by our Institutional Review Board and Ethics Committee. Informed consent was carefully obtained from all study participants.

\section{Study Population}

From January 2007 to January 2010, 25 pregnant women were consecutively enrolled in our study. The study participants were those patients whose fetuses were suspected to have $\mathrm{CL}$ or $\mathrm{CP}$ as a result of routine screening US scans in the obstetrics clinic of our center, followed by a referral to the radiology department for targeted US scans. There were no multiple gestation cases, so a total of 25 fetuses were evaluated in this study. The mean maternal age was 31.2 years old (range, 26 to 39 years). The mean gestational age at the time of the targeted US was 25.6 weeks old (range, 18.5 to 36.0 weeks). The characteristics of study participants are summarized in Table 1.

\section{Targeted Ultrasound}

All targeted US was performed by a radiologist (J.Y.C.) with 17 years of experience in maternal-fetal radiology and ultrasound examination using an Acuson Sequoia 512 ultrasound machine with a 2-4-MHz curved probe and a 5-8-MHz sector probe (Acuson Corp., Mountain View, CA, USA). In all cases, coronal and axial images of the upper lip were obtained. Axial images of the maxillary alveolar arch were analyzed for the existence of defects in and malalignment of the alveolar arch. Attempts were made to obtain mid-sagittal images to evaluate the existence of hard palate defects. This was followed by attempts to obtain sagittal color Doppler ultrasonograms during fetal breathing or swallowing to detect bidirectional amniotic fluid flow through the defect. Before evaluating the mid-sagittal plane, the upper lip was visualized and evaluated on the coronal plane. Then, the probe was rotated to the sagittal plane using the fetal nose as the pivot axis. The mid-sagittal plane was defined as the sagittal ultrasonogram of the fetal face containing forehead, nasal bone, vomer, philtrum, lower lip, and the tip of chin in one plane. To detect low-velocity flow through a palatine defect, the wall filter was set as low as possible, and color gain was set as high as possible without noise. The range of total examination time was from 8 to 53 minutes, and the mean examination time was $26.2 \pm 16.8$ minutes. The examination time of the sagittal plane with color Doppler only was not recorded; however, this was assumed to 
have taken approximately 5 minutes.

\section{Image Analysis}

All targeted US findings were compared to postnatal findings based on hospital records made by experienced obstetricians. Clefts were categorized by location and extent (involving lips, alveolus, and palate) and by laterality (unilateral, bilateral, or midfacial) in both the targeted US and postnatal findings. Four imaging findings (i.e., alveolar defect in an axial scan, alveolar malalignment in an axial scan, palatal echo defect in a sagittal scan, and flow-through defect in a sagittal CDUS image) were documented in each case. The existence rates of each finding for each fetus with $C L$ with $C P$ or isolated $\mathrm{CL}$ were calculated. Finally, the accuracy of detecting $\mathrm{CL}$ with or without $\mathrm{CP}$ using a combined scan of axial and sagittal images, including CDUS images, was also calculated.

\section{Results}

All of the 25 fetuses were confirmed postnatally to have an orofacial cleft. Among them, 17 had $\mathrm{CL}$ with $\mathrm{CP}$ and eight had isolated $\mathrm{CL}$ only (CL without $\mathrm{CP}$ ). Four of the eight isolated $\mathrm{CL}$ cases had a cleft alveolus. Due to weak fetal swallowing, a sagittal CDUS could not be obtained in four out of the 25 cases (three out of $17 \mathrm{CL}$ with CP cases and one out of eight isolated $\mathrm{CL}$ case).

An alveolar defect in an axial image was detected in 16 out of 17 cases of $\mathrm{CL}$ with $\mathrm{CP}(94.1 \%)$, and in four out of eight (50\%) isolated $\mathrm{CL}$ cases. The overall accuracy for diagnosing $\mathrm{CL}$ with or without $\mathrm{CP}$ using the finding of an alveolar defect in an axial image was $80 \%$ (20 out of 25 cases). Alveolar malalignment was detected in 11 out of 17 cases of $C L$ with CP (57.8\%); however, it was not detected in any cases of isolated CL. Palate echo defects in sagittal scans were detected in 14 of 17 cases (82.4\%). Communicating

Table 1. Summary of study populations

\begin{tabular}{|c|c|c|c|c|c|c|c|c|}
\hline $\begin{array}{l}\text { Case } \\
\text { No. }\end{array}$ & $\begin{array}{l}\text { Maternal } \\
\text { age (yr) }\end{array}$ & $\begin{array}{c}\text { GA at US } \\
\text { (wk) }\end{array}$ & $\begin{array}{l}\text { Sagittal US } \\
\text { grayscale }\end{array}$ & Sagittal CDUS & $\begin{array}{c}\text { Arch } \\
\text { defect }\end{array}$ & $\begin{array}{l}\text { Arch mal- } \\
\text { alignment }\end{array}$ & US diagnosis & Postnatal diagnosis \\
\hline 1 & 34 & 27.5 & Nonspecific & No transpalatal flow & - & - & Cleft lip & Cleft lip \\
\hline 2 & 33 & 21.4 & Nonspecific & No transpalatal flow & + & + & Cleft lip and palate & Cleft lip and palate \\
\hline 3 & 28 & 36.0 & Hard palate defect & $(+)$, flow through defect & + & - & Cleft lip and palate & Cleft lip and alveolus \\
\hline 4 & 31 & 22.0 & Hard palate defect & Could not acquired & + & - & Cleft lip and palate & Cleft lip and palate \\
\hline 5 & 34 & 20.0 & Hard palate defect & Could not acquired & + & + & Cleft lip and palate & Cleft lip and palate \\
\hline 6 & 33 & 34.4 & Hard palate defect & Could not acquired & + & + & Cleft lip and palate & Cleft lip and palate \\
\hline 7 & 33 & 30.2 & Hard palate defect & $(+)$, flow through defect & + & + & Cleft lip and palate & Cleft lip and palate \\
\hline 8 & 30 & 30.1 & Hard palate defect & (+), flow through defect & + & + & Cleft lip and palate & Cleft lip and palate \\
\hline 9 & 32 & 26.4 & Hard palate defect & No transpalatal flow & + & Equivocal & Cleft lip and alveolus & Cleft lip and alveolus \\
\hline 10 & 38 & 21.3 & Hard palate defect & $(+)$, flow through defect & + & + & Cleft lip and palate & Cleft lip and palate \\
\hline 11 & 34 & 31.5 & Hard palate defect & $(+)$, flow through defect & + & - & Cleft lip and palate & Cleft lip and palate \\
\hline 12 & 31 & 25.0 & Hard palate defect & $(+)$, flow through defect & + & + & Cleft lip and palate & Cleft lip and palate \\
\hline 13 & 29 & 28.2 & Hard palate defect & $(+)$, flow through defect & + & - & Cleft lip and palate & Cleft lip and palate \\
\hline 14 & 32 & 18.5 & Hard palate defect & $(+)$, flow through defect & + & - & Cleft lip and palate & Cleft lip and palate \\
\hline 15 & 28 & 37.0 & Nonspecific & No transpalatal flow & - & - & Cleft lip & Cleft lip and alveolus \\
\hline 16 & 26 & 21.3 & Nonspecific & No transpalatal flow & - & - & Cleft lip & Cleft lip \\
\hline 17 & 30 & 21.6 & Nonspecific & No transpalatal flow & + & - & Cleft lip & Cleft lip and alveolus \\
\hline 18 & 39 & 27.3 & Nonspecific & No transpalatal flow & - & - & Cleft lip & Cleft lip \\
\hline 19 & 24 & 34.4 & Nonspecific & No transpalatal flow & + & + , mild & Cleft lip and alveolus & Cleft lip and palate \\
\hline 20 & 26 & 26.2 & Nonspecific & $(+)$, flow through defect & - & - & Cleft lip and palate & Cleft lip and palate \\
\hline 21 & 37 & 25.1 & Nonspecific & Could not acquired & + & - & Cleft lip and alveolus & Cleft lip and alveolus \\
\hline 22 & 32 & 30.0 & Hard palate defect & $(+)$, flow through defect & + & + & Cleft lip and palate & Cleft lip and palate \\
\hline 23 & 30 & 22.5 & Hard palate defect & $(+)$, flow through defect & + & + & Cleft lip and palate & Cleft lip and palate \\
\hline 24 & 28 & 22.0 & Hard palate defect & $(+)$, flow through defect & + & - & Cleft lip and palate & Cleft lip and palate \\
\hline 25 & 27 & 35.0 & Hard palate defect & $(+)$, flow through defect & + & + & Cleft lip and palate & Cleft lip and palate \\
\hline
\end{tabular}

GA, gestational age; CDUS, Color Doppler ultrasonography; US, ultrasonography. 
flow-through defects in the sagittal CDUS were identified in 12 of 17 cases (70.6\%) of CL with CP (Fig. 1).

Case 20 showed no definite defect in the hard palate, but a transpalatal communicating flow was detected in the sagittal CDUS. Therefore, we suggested the possibility of a diagnosis of $C L$ with CP based on the finding in the sagittal CDUS, confirmed by postnatal neonate examination.

Case 9 showed a suspicious hard palate defect on the grayscale scan and was initially considered to be $\mathrm{CL}$ with $\mathrm{CP}$. However, there was no definite transpalatal communicating flow on consecutive sagittal CDUS. The US diagnosis was reported as CL with alveolar involvement and confirmed by postnatal neonate examination (Fig. 2).

Case 3 showed a hard palate defect in the sagittal grayscale ultrasound and a transpalatal flow in the CDUS; these were confirmed as an isolated $\mathrm{CL}$ with alveolar defect. It was suggested that the flow through the alveolar cleft had been improperly

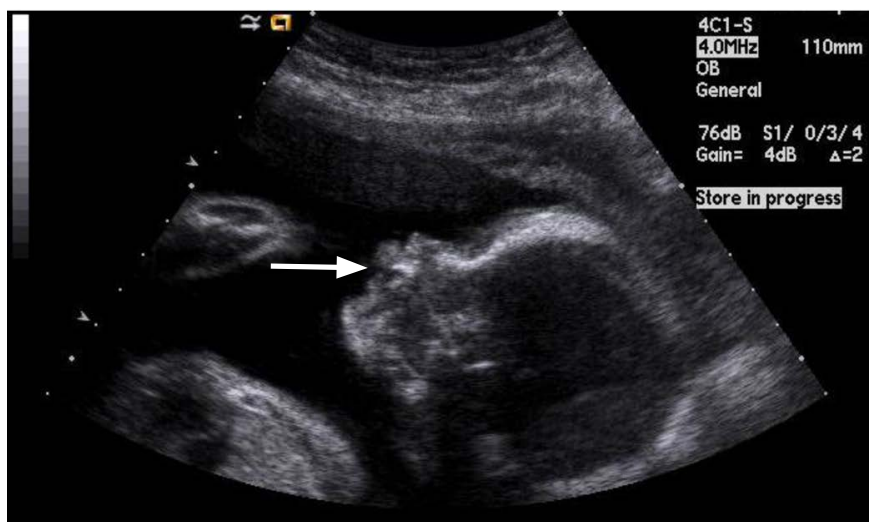

A

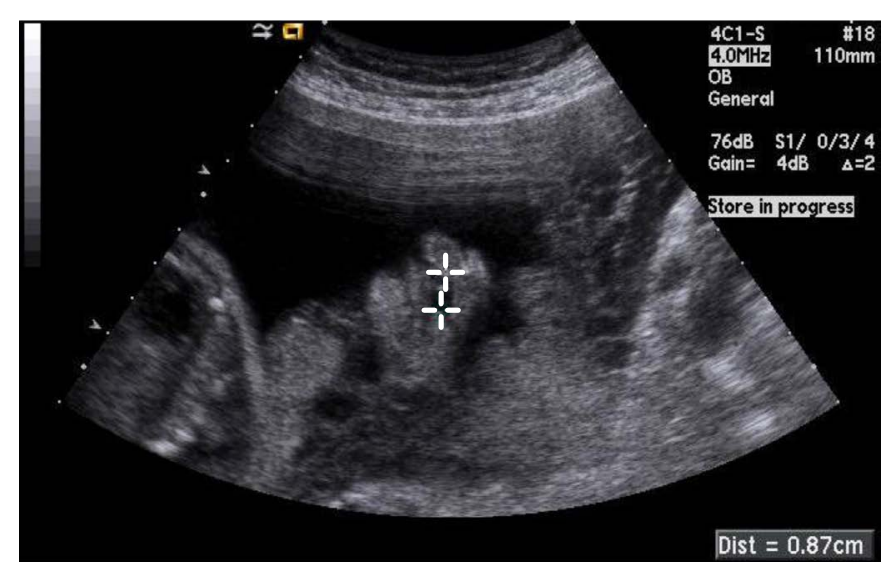

C identified as transpalatal flow in the CDUS.

The sensitivity, specificity, positive predictive values (PPV), negative predictive values (NPV), and accuracy of each of the parameters (i.e., alveolar arch defect in an axial scan, alveolar malalignment in an axial scan, hard palate defect in a sagittal scan, transpalatal flow in a CDUS, and combined US interpretation using all parameters) for differentiating $\mathrm{CL}$ with $\mathrm{CP}$ from isolated $\mathrm{CL}$ are summarized in Table 2. Sagittal CDUS presented slightly improved sensitivity, accuracy, and PPV compared to sagittal grayscale scan $(85.71 \%$ vs. $82.35 \%$ sensitivity, $85.71 \%$ vs. $80.00 \%$ PPV, and $92.31 \%$ vs. $87.50 \%$ accuracy, respectively). The combined US interpretation of all parameters showed good diagnostic performance, with $94.12 \%$ sensitivity, $94.12 \% \mathrm{PPV}$, and $91.67 \%$ accuracy.

\section{Discussion}

The standard US evaluation method of fetal upper lip and anterior

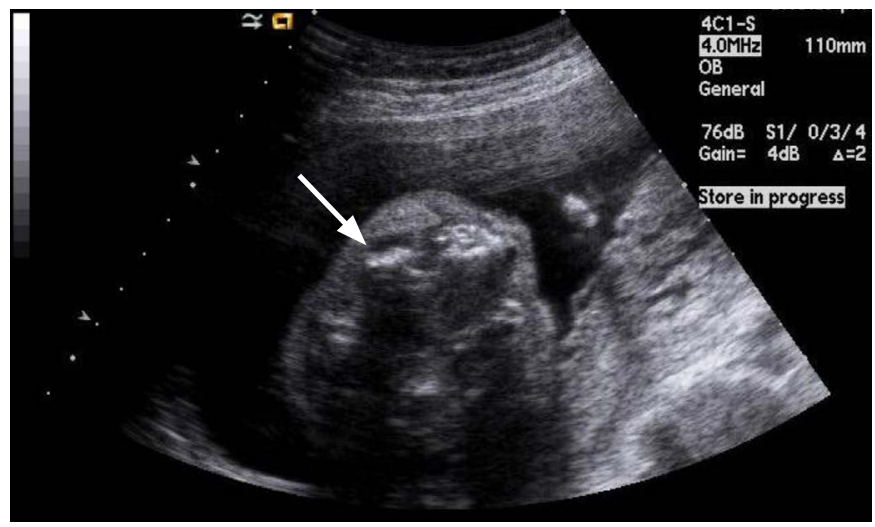

B

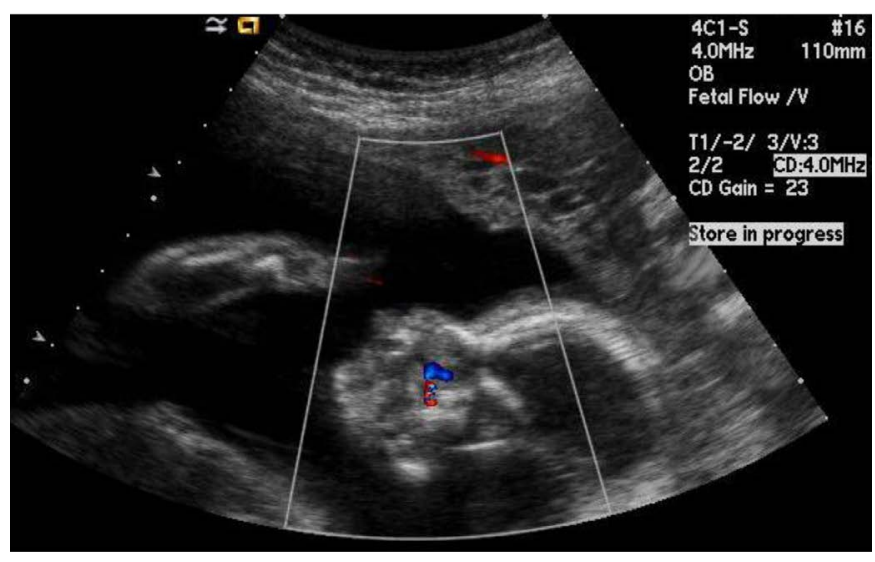

D

Fig. 1. Prenatal ultrasonographic findings of cleft lip and palate in a 27-week fetus.

A. Sagittal image of upper lip shows narrow defect of upper lip (arrow). B. Axial image of upper alveolar shows a small alveolar defect and malalignment (arrow). C. Coronal image of the hard palate reveals approximately $0.9 \mathrm{~cm}$ long defect on the hard palate. D. Color Doppler sonogram shows flow through the hard palate defect. 
Table 2. Sensitivity, specificity, positive and negative predictive values, and accuracy of each parameter

\begin{tabular}{|c|c|c|c|c|c|}
\hline & $\begin{array}{l}\text { Arch defect on axial } \\
\text { grayscale scan }\end{array}$ & $\begin{array}{l}\text { Arch malalignment on } \\
\text { axial grayscale scan }\end{array}$ & $\begin{array}{l}\text { Hard palate defect on } \\
\text { sagittal grayscale scan }\end{array}$ & $\begin{array}{l}\text { Transpalatal flow on } \\
\text { sagittal CDUS }\end{array}$ & $\begin{array}{c}\text { Combined US } \\
\text { interpretation using } \\
\text { all parameters }\end{array}$ \\
\hline Sensitivity (\%) & 94.12 & 64.71 & 82.35 & 85.71 & 94.12 \\
\hline Accuracy (\%) & 80.00 & 76.00 & 80.00 & 85.71 & 91.67 \\
\hline Positive predictive value (\%) & 80.00 & 100.00 & 87.50 & 92.31 & 94.12 \\
\hline Odds ratio & 16.00 & N/A & 14.00 & 36.00 & 96.00 \\
\hline Relative risk & 4.00 & 2.33 & 2.63 & 3.69 & 6.59 \\
\hline
\end{tabular}

CDUS, Color Doppler ultrasonography; US, ultrasonography; N/A, non-accessible due to zero false positives in this study.

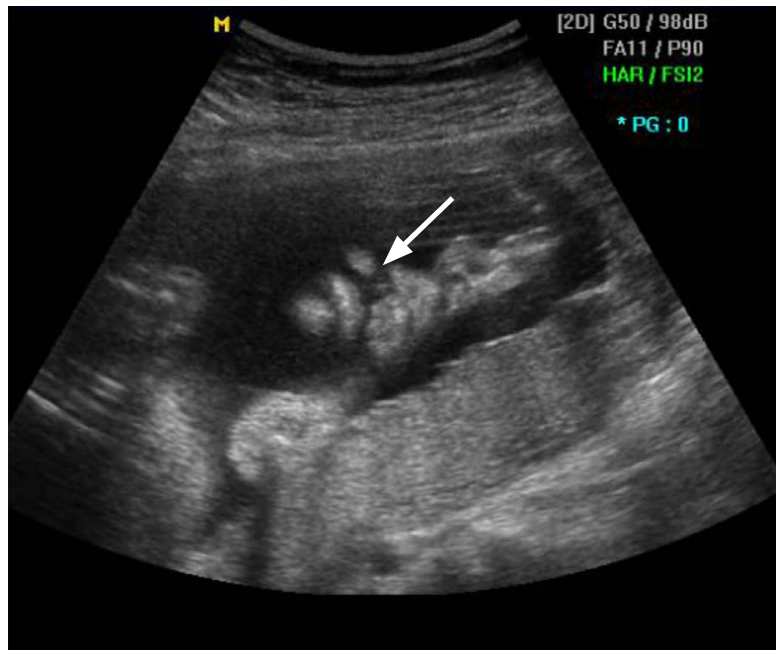

A

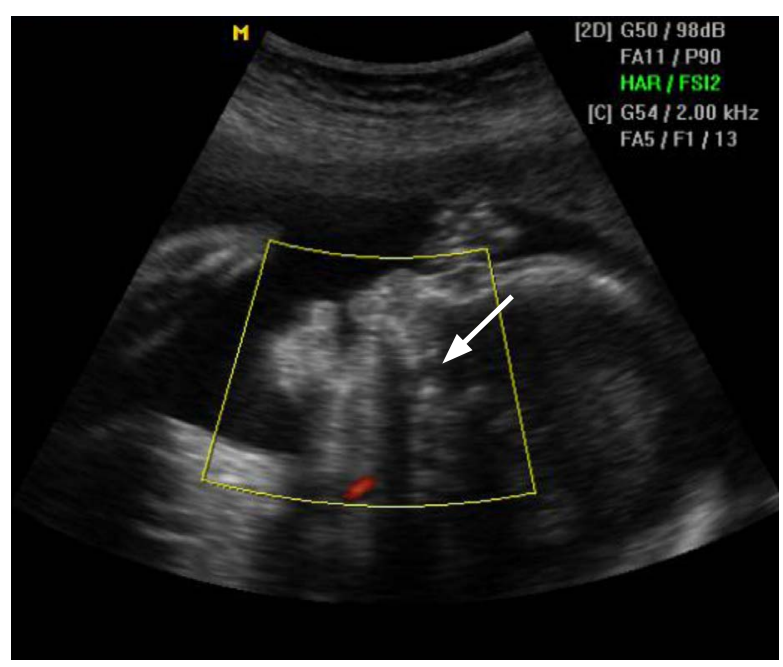

C

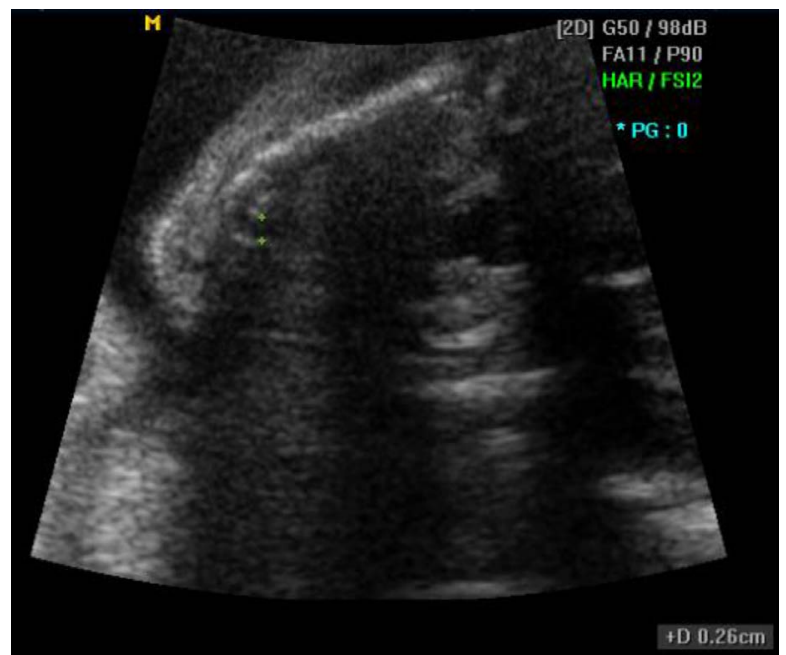

B

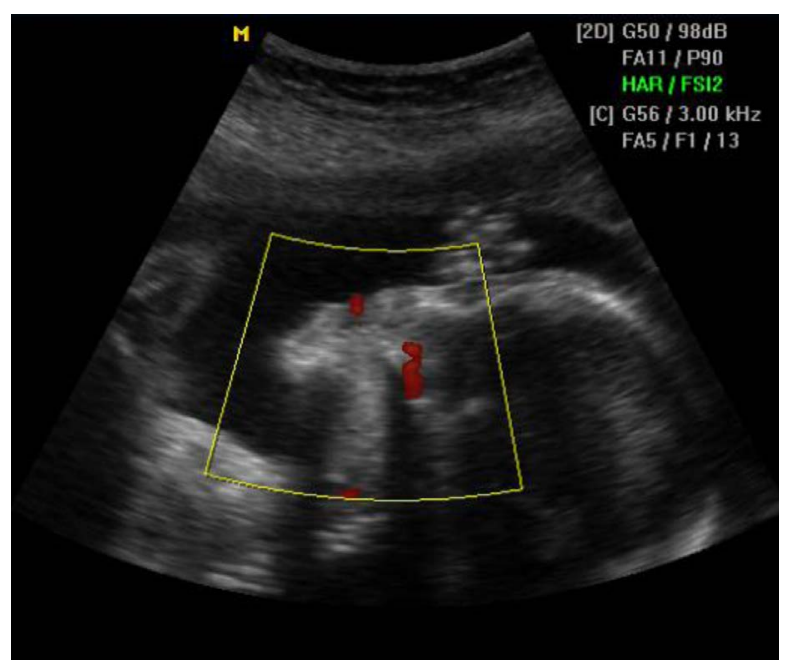

D

Fig. 2. Prenatal ultrasonographic findings of cleft lip with alveolar involvement in a 26.4 week fetus.

A. Coronal image of the upper lip shows a defect of upper lip (arrow). B. Axial image of the alveolar arch shows a small alveolar arch defect (annotated). Arch malalignment is equivocal. C. Sagittal image of the hard palate reveals suspicious focal defect on the hard palate (arrow). D. Color Doppler sonogram shows no definite flow through the hard palate defect. 
palate for cleft consists of coronal and axial plane assessment of midfacial anatomy [14]. Although adding fetal facial scans to routine screening 2-D US has been considered optimal [15], the accuracy for detecting $\mathrm{CL}$ with or without $\mathrm{CP}$ is variable, especially in low-risk patients [5]. Hence, some efforts to improve the detection rate of $\mathrm{CL}$ with or without $\mathrm{CP}$ have been attempted by adding the sagittal view to the evaluation.

However, detection of a defected palate in a grayscale sonogram is difficult due to acoustic shadowing from the bony alveolar ridge and maxilla [13]. The importance of a sagittal scan, therefore, has been described with a limited view toward detecting "premaxillary protrusion(s)" when bilateral CL with or without CP was suspected in coronal or axial scans. Babcook et al. [16] reported that the echogenic fusion line of the secondary palate was seen in only $26 \%$ of in utero fetuses in sagittal sonograms and in $100 \%$ of normal fetal specimens.

Delineating the palatine defect by visualization of the slow amniotic flow through the defect using sagittal CDUS has been tried in some case reports [11-13] to increase the detection rate of $\mathrm{CL}$ with or without $\mathrm{CP}$ by collecting additional information through sagittal US scans. In this study, we extended the methods to a larger group of high-risk patients.

In our study, the accuracy of observing flow in sagittal CDUS to detect $\mathrm{CL}$ with CP was $85.7 \%$ (CL with CP, 12 out of 14 cases; $\mathrm{CL}$ without $\mathrm{CP}$, one out of seven cases showed transpalatal flow in sagittal CDUS). This result is a high detection rate compared to previous studies showing $41 \%-46 \%$ for detection of $\mathrm{CL}$ with CP $[6,7]$, which highlights the diagnostic value of adding sagittal CDUS to fetal facial US. For these previous studies, the $\mathrm{CL}$ with $\mathrm{CP}$ detection rate of 3-D US was $86 \%-90 \%$. Thus, the results of our study suggest that by only adding sagittal CDUS to fetal facial US, are detection rates similar those achieved using 3-D US to detect $\mathrm{CL}$ with CP possible. Detection of palate defects directly in sagittal images or flow in sagittal CDUS showed comparable, or better, accuracy than axial scans for $\mathrm{CL}$ with $\mathrm{CP}$ (detecting alveolar defects or alveolar malalignment). We infer from this that the sagittal scan with CDUS is a feasible and useful scanning method to detect $C L$ with $\mathrm{CP}$; our high detection rate compared to previous studies can be explained by the use of sagittal CDUS.

We found that the accuracy of detecting $\mathrm{CL}$ with $\mathrm{CP}$ by delineating a hard palate defect on the grayscale sagittal US was successful (accuracy of $80 \%$ ). Rotten and Levaillant [17] described sonographic characteristics of secondary palate clefts in sagittal US scans. They reported that viewing defects in hard palate continuity was possible and that the defects were asymmetric. However, they did not report the detection accuracy of a sagittal scan alone, and concluded that the secondary palate was best seen in coronal scans with $87 \%$ concordance between the US report and postnatal evaluation. In our study, we reported comparable accuracy as reported by Rotten et al. [17], supporting our hypothesis that sagittal US scans may have additional value in the diagnosis of $\mathrm{CL}$ with or without $\mathrm{CP}$.

Though similar in accuracy, sagittal CDUS had the slight advantage of increasing specificity, PPV, and NPV compared to detecting hard palate defects in sagittal grayscale scans. A combined US interpretation of all parameters could show good diagnostic performance, with up to $94 \%$ of sensitivity, $94 \%$ of PPV, and $92 \%$ of accuracy. The odds ratio and relative risk of sagittal CDUS were better than that of sagittal grayscale scans; positive findings of sagittal CDUS were better correlated with the existence of actual CPs than those of sagittal grayscale scans. Thus, sagittal CDUS should be added to a routine sagittal grayscale sonogram. Occasionally, there can be cases of $\mathrm{CL}$ without $\mathrm{CP}$ that show alveolar arch defects or malalignment in sagittal grayscale sonogram. In those cases, performing sagittal CDUS for visualizing transpalatal flow can help in distinguishing true CP from artifacts (Fig. 1), strengthening the added value of sagittal CDUS.

By combining axial and sagittal sonograms with CDUS, the diagnostic accuracy was $92 \%$ (approximately 10\% higher than using axial images alone). Our results had comparable accuracy with previous studies [6-8], in which the accuracy of 2-D US to detect CL with or without CP ranged from $90 \%$ to $96 \%$. However, limiting the perspective to $\mathrm{CL}$ with $\mathrm{CP}$, the accuracy of previous studies were relatively low $(31 \%-46 \%)[6,8]$. Our study showed $94.1 \%$ accuracy; using a combination of axial and sagittal images with CDUS had 16 accurate diagnoses out of 17 total. In a real clinical setting, differentiation from $\mathrm{CL}$ with alveolar defect or malalignment without $\mathrm{CP}$ and $\mathrm{CL}$ with $\mathrm{CP}$ is crucial; the former requires a less complex surgical correction (usually a one-stage operation) and shows better clinical outcomes in terms of permanent deformity, phonation, and velopharyngeal insufficiency compared to the latter. Based on our results, we suggest adding sagittal US with CDUS on conventional axial and coronal US of fetal faces to provide the additional benefit of a high NPV (85.7\%) compared to grayscale scans, consequently increasing the overall accuracy for differentiating $\mathrm{CL}$ with alveolus involvement without $\mathrm{CP}$ and $\mathrm{CL}$ with $\mathrm{CP}$.

Our study has several limitations. First, the population we studied was relatively small. Second, this population was limited to highrisk cases that had been referred to tertiary care centers due to abnormal findings on screening US. Future studies with larger, lowrisk populations (those subject to routine screening) are needed to validate and generalize our results and conclusions. Third, although uncommon, there could be possibilities of false positives (i.e., mistaking flow-through alveolar clefts for transpalatal flow) or false negatives (i.e., due to insufficient fetal swallowing motion) 
of sagittal CDUS. Furthermore, the yield of sagittal CDUS can be variable based on whether the fetus swallows or breathes during the examination. We note that we were not able to obtain sagittal CDUS from $16 \%$ (four out of 25 ) of our study participants. The yield and average additional examination time of getting sagittal CDUS must be assessed through studies of large, low-risk populations to evaluate the validity of adding sagittal US with CDUS to routine fetal facial scan protocols.

Despite these limitations, we can conclude that sagittal US evaluation of the fetal hard palate is a feasible method to directly reveal bony defects of the hard palate and communicating amniotic fluid flow through the defect using CDUS. Adding sagittal scans with CDUS as a part of a routine sonographic fetal face evaluation protocol may have additional value in the differential diagnosis of fetal CL with, or without, CP.

ORCID: Myoung Seok Lee: http://orcid.org/0000-0001-5285-4874; Jeong Yeon Cho: http://orcid.org/0000-0001-8659-0918; Sang Youn Kim: http://orcid.org/0000-00034038-7345; Seung Hyup Kim: http://orcid.org/0000-0002-9339-5907; Joong Shin Park: http://orcid.org/0000-0002-5246-0477; Jong Kwan Jun: http://orcid.org/00000002-0242-1736

\section{Conflict of Interest}

No potential conflict of interest relevant to this article was reported.

\section{Acknowledgments}

This research was supported by a grant of the Korea Health Technology R\&D Project through the Korea Health Industry Development Institute (KHIDI), funded by the Ministry of Health \& Welfare, Republic of Korea (grant number : HI15C1532).

\section{References}

1. World Health Organization. Global registry and database on craniofacial anomalies: report of a WHO Registry Meeting on Craniofacial Anomalies. Geneva: World Health Organization, 2003.

2. Mossey PA, Little J, Munger RG, Dixon MJ, Shaw WC. Cleft lip and palate. Lancet 2009;374:1773-1785.

3. Nyberg DA, Sickler GK, Hegge FN, Kramer DJ, Kropp RJ. Fetal cleft lip with and without cleft palate: US classification and correlation with outcome. Radiology 1995; 195:677-684.

4. Berge SJ, Plath H, Van de Vondel PT, Appel T, Niederhagen B, Von Lindern JJ, et al. Fetal cleft lip and palate: sonographic diagnosis, chromosomal abnormalities, associated anomalies and postnatal outcome in 70 fetuses. Ultrasound Obstet Gynecol 2001;18:422431.

5. Maarse W, Berge SJ, Pistorius L, van Barneveld T, Kon M, Breugem $C$, et al. Diagnostic accuracy of transabdominal ultrasound in detecting prenatal cleft lip and palate: a systematic review. Ultrasound Obstet Gynecol 2010;35:495-502.

6. Johnson DD, Pretorius $\mathrm{DH}$, Budorick NE, Jones MC, Lou KV, James $\mathrm{GM}$, et al. Fetal lip and primary palate: three-dimensional versus two-dimensional US. Radiology 2000;217:236-239.

7. Chmait $R$, Pretorius $D$, Jones $M$, Hull $A$, James $G$, Nelson $T$, et al. Prenatal evaluation of facial clefts with two-dimensional and adjunctive three-dimensional ultrasonography: a prospective trial. Am J Obstet Gynecol 2002;187:946-949.

8. Wang LM, Leung KY, Tang M. Prenatal evaluation of facial clefts by three-dimensional extended imaging. Prenat Diagn 2007;27:722729.

9. Campbell S, Lees C, Moscoso G, Hall P. Ultrasound antenatal diagnosis of cleft palate by a new technique: the 3D "reverse face" view. Ultrasound Obstet Gynecol 2005;25:12-18.

10. Platt LD, Devore GR, Pretorius DH. Improving cleft palate/cleft lip antenatal diagnosis by 3-dimensional sonography: the "flipped face" view. J Ultrasound Med 2006;25:1423-1430.

11. Aubry MC, Aubry JP. Prenatal diagnosis of cleft palate: contribution of color Doppler ultrasound. Ultrasound Obstet Gynecol 1992;2:221224.

12. Sherer DM, Abramowicz JS, Jaffe R, Woods JR Jr. Cleft palate: confirmation of prenatal diagnosis by colour Doppler ultrasound. Prenat Diagn 1993;13:953-956.

13. Kennelly MM, Moran P. Directional Power Doppler in the midsagittal plane as an aid to the prenatal diagnosis of cleft lip and palate. Prenat Diagn 2008;28:56-58

14. Babcook CJ. The fetal face and neck. In: Callen PW, ed. Ultrasonography in obstetrics and gynecology. 4th ed. Philadelphia, PA: W.B.Saunders, 2000;307-330.

15. Royal College of Obstetricians and Gynecologists. Report of the RCOG Working Party on Ultrasound Screening for Fetal Abnormalities. London: Royal College of Obstetricians and Gynaecologists, 1997.

16. Babcook CJ, McGahan JP, Chong BW, Nemzek WR, Salamat MS. Evaluation of fetal midface anatomy related to facial clefts: use of US. Radiology 1996;201:113-118.

17. Rotten D, Levaillant JM. Two- and three-dimensional sonographic assessment of the fetal face. 2. Analysis of cleft lip, alveolus and palate. Ultrasound Obstet Gynecol 2004;24:402-411. 